\title{
The Challenges of Professional Development in the Evolving World of Pharmacy Education
}

\author{
Carol Motycka ${ }^{1, *}$, Jennifer S. Williams ${ }^{2}$, Thanh Hogan ${ }^{3}$, Matthew Gray ${ }^{1} \&$ Jennifer Hartman $^{1}$ \\ ${ }^{1}$ University of Florida College of Pharmacy, Jacksonville, FL 32209, USA \\ ${ }^{2}$ University of Florida College of Pharmacy, Seminole, FL 33772, USA \\ ${ }^{3}$ UF Health, Jacksonville FL 32209, USA \\ *Corresponding author: University of Florida College of Pharmacy, 580 W. 8th Street, Jacksonville, FL 32209, USA. \\ Tel: 1-904-244-9590. E-mail: motycka@cop.ufl.edu
}

Received: November 4, 2013

Accepted: November 14, $2013 \quad$ Online Published: May 9, 2014

doi:10.5430/jct.v3n1p94

URL: http://dx.doi.org/10.5430/jct.v3n1p94

\begin{abstract}
The primary purpose of schools and colleges of pharmacy is to produce pharmacists capable of providing competent patient centered care. To accomplish this goal, pharmacy students must learn and retain a great deal of knowledge as well as develop professional attitudes and behaviors. In recent years, several articles have been published questioning the professionalism of pharmacy students and whether colleges of pharmacy are promoting professionalism (Hammer, 2003; Chisholm, 2004). Professionalism has a broad definition and encompasses every aspect of the duty of a pharmacist. The definition of professionalism and a discussion of professional socialization roadblocks are important considerations when establishing guidance to students and faculty. Responsibilities of the student and responsibilities of the educator should be clear to all involved. E-professionalism presents a new consideration when outlining professionalism standards to pharmacy students and should be addressed as well. Colleges of pharmacy must develop methodologies to aid in the development of professionalism among pharmacy students in all types of learning environments, whether a student attends a traditional campus or a distance campus. Finally, with the implementation of distance campuses, professionalism is presented with new and unique challenges which require continuous evaluation to prevent negative outcomes.
\end{abstract}

Keywords: professionalism; distance pharmacy education

\section{Introduction}

The primary purpose of schools and colleges of pharmacy is to produce pharmacists capable of providing competent patient centered. To accomplish this goal, students must learn and retain a great deal of knowledge as well as develop professional attitudes and behaviors. In recent years, several articles have been published questioning the professionalism of pharmacy students and whether colleges of pharmacy are promoting professionalism (Hammer, 2003; Chisholm, 2004). In response to this, the American Pharmaceutical Association (APhA), Academy of Students of Pharmacy (ASP), and the American Association of Colleges of Pharmacy (AACP) Committee on Student Professionalism developed a "Pharmacy Professionalism Toolkit for Students and Faculty" (2011). This toolkit can be utilized as a resource for specific activities and strategies for faculty to build into students' curriculum to promote and assess professionalism on their own campus.

Educators need to address professionalism with students, because while professionalism has a broad definition, it encompasses every aspect of the duty of a pharmacist-from generic mundane tasks like filing reports to exceptionally altruistic acts like taking the initiative to help a patient in need. Professionalism should be woven into either environment. While media reports of professionals, role-models, and high ranking officials engaging in unethical, immoral, and even criminal behavior have become increasing prevalent, Gallup polls have reported that pharmacists are held in high esteem by the public and consistently rank high in polls for trust, ethics and honesty (Jones, 2010). Educators must advocate for maintaining the highest level of professionalism standards among students, because the lack of professionalism can break the bonds of trust and respect between healthcare 
professionals and their patients. No profession is immune from unprofessional behavior entirely, and pharmacy has known unethical, greedy, and uncaring practitioners. CNBC reported, in an episode of American Greed, the case of Robert Courtney, a pharmacist who profited millions by dispensing watered down forms of chemotherapy drugs to patients (CNBC, 2011). Individual acts like that of Courtney are coupled with considerable changes in our healthcare system which over the last decade may have undermined the professionalism standards in pharmacy. For example, cost reduction strategies, bonuses for increased prescription sales, and a shortage of pharmacists have all had a negative impact on patient care (Knapp, 2005; Chisholm, 2006). Pharmacy practice began to lose its focus on patient care, and this loss of professionalism has trickled down into our pharmacy schools. We now see pharmacy students dressed unprofessionally wearing jeans and flip-flops, demonstrating a lack of respect by coming to class tardy, and some students engaging in unethical behaviors like plagiarism. When seeking to re-establish professionalism in our schools, the process of teaching professionalism to students raises many questions. These questions are re-addressed when we consider professionalism in a distance campus setting, because we rely on fewer staff members and video conference sessions for communication and teaching. Therefore, are students at a distance campus provided the same opportunities for professional growth as students at a traditional campus? What is e-professionalism and how do we display it? Is professionalism something that can be learned, or is it an attribute that a student already possesses? What can potentially inhibit the development of professionalism? What responsibility do pharmacy educators have in teaching professionalism? What are the responsibilities of the pharmacy student? How do we measure professionalism? The following discussion will focus on the development of professionalism in pharmacy students both in traditional and a distance campus environments and will provide some answers to these questions.

\section{Definitions}

For the scope of this review, it is important to fully understand what contributes to and serves as professionalism. Professional socialization or professionalization can be defined as: "The process of inculcating a profession's attitudes, values, and behaviors in a professional” (APhA/AACP, 2000). Since professionalism can have a very broad definition, faculty members through discussions with their colleagues and guidance from professional organizations must come to an agreement as to which traits describe a professional in their field of practice. According to the White Paper on Pharmacy Student Professionalism, pharmacists and pharmacy students act professionally when they display the following 10 traits (APhA/AACP, 2000; National Institute of Business Management, 1991):

- Knowledge and skills of a profession

- Commitment to self-improvement of skills and knowledge

- Service orientation

- Pride in the profession

- Covenantal relationship with the client

- Creativity and innovation

- Conscience and trustworthiness

- Accountability for his/her work

- Ethically sound decision making

- Leadership

Additionally in 2001, the American Board of Internal Medicine (ABIM) described the following three commitments as key elements in displaying professionalism (2001)

- A commitment to the highest standards of excellence in the practice of medicine and in the generation and dissemination of knowledge.

- A commitment to sustain the interests and welfare of patients.

- A commitment to be responsive to the health needs of society.

The ABIM went on to define six tenets that one must possess in order to fulfill these three commitments. These tenets include altruism, accountability, excellence, duty, honor and integrity, and respect for others (Chisholm, 2006). Although originally defined for academic medicine these tenets have been adapted specifically for pharmacists by Hammer and colleagues in 2003 (Hammer, 2003). Table 1 provides definitions of the six tenets of professionalism as they apply to pharmacists (Chisholm, 2006; Hammer 2003; ABIM, 2001). For pharmacy educators there have been 
concerns regarding whether these traits and tenets can be taught or if students already possesses them upon entering pharmacy school, and in the latter case, if these skills are simply honed during their matriculation (ASHP, 2008; Roth, 2009). To successfully instill the traits of a professional, faculty members must lead by example and develop as role models and mentors to pharmacy students. In turn, students should be actively involved with a quality mentor early in their education, so professionalism can be fostered and developed successfully over time. The slow growth and continued re-evaluation can prevent the formation of bad habits and can prevent the hindrance of many roadblocks (APhA/AACP, 2000; ASHP, 2008; Roth; 2009). This article will explore the process by which pharmacy students develop professional socialization followed by a discussion of the factors influencing professional development when students also learn at a distance.

Table 1. The Six Tenets of Professionalism, Adapted for Pharmacists ${ }^{1,5}$

1. Altruism: Pharmacists must serve the best interest of patients above their own or above that of employers. This means that care is not compromised or reduced in quality because of a patient's inability to pay.

2. Accountability: Pharmacists are accountable for fulfilling the implied covenant that they have with their patients. They are also accountable to society for addressing the health needs of the public and to their profession for adhering to pharmacy's code of ethical conduct.

3. Excellence: Pharmacists must be committed to lifelong learning and knowledge acquisition or retrieval to serve patients.

4. Duty: Pharmacists must be committed to serving patients even when it is inconvenient to the pharmacist. The pharmacist is an advocate for the appropriate care of the patient even if payment cannot be made

5. Honor and Integrity: The pharmacist must be fair, truthful, keep his/her word, meet commitments, and be straightforward. They also recognize the possibility of conflict of interest and avoid relationships in which personal gain supersedes the best interest of the patient.

6. Respect for Others: Pharmacists must respect other pharmacists, health professionals, patients and their families.

\section{Professional Socialization Roadblocks}

As pharmacy student progress through the curriculum, they will be faced with many challenges and obstacles. Many of these roadblocks will be related to academic achievements, development of an adequate knowledge base, and time management; however students will also face challenges in developing professional relationships with faculty and fellow classmates. Although these trials may prove to be beneficial in the maturity and character development of the student, they can also serve as a hindrance in the professional socialization process (APhA/AACP, 2000; Roth, 2009; Prince, 2003). In order to accurately and effectively perform the responsibilities of a pharmacist, the student needs to acquire an extensive knowledge base and possess problem solving abilities. However, displaying a high level of professionalism and leadership is equally as important as these academic endeavors (Prince, 2003; Cruess, 2006). While faculty mentoring is a valuable tool in professionalization, students frequently receive conflicting messages from different preceptors and faculty members which can cause confusion and ultimately inhibit the professionalization process. As students become more and more involved with practicing pharmacists, they can receive mixed signals on their future role as a healthcare provider. These experiences may cause frustration or disappointment to students as they transition from the classroom to the "real world" of pharmacy and their expectations remain unfulfilled. This phenomenon has been described as "realistic disenchantment" or "disillusionment” and can have a profound effect on students attitudes and behaviors (Doshi, 2003; Chalmers, 1995).

To combat this issue, pharmacy students should be exposed to real-life pharmacy practices early in their education and then debriefed on how the experience was received. This discussion can assist the instructor in detecting possible unrealistic expectations of the student. Pharmacy preceptors should frequently assess how their personality, attitudes, practice environment and work ethic might be interpreted by a student. The old saying, "People are a product of their environment" can also be applied to the professional development of pharmacy students. Exposure to an unprofessional environment could result in negative outcomes for the developing student. Therefore, some important questions preceptors should ask themselves include: am I consistently punctual for the activities that I scheduled with the student? Am I providing the student with an acceptable amount of my time, or am I too busy working and not 
interacting with the student? Am I assigning tasks that are educational and beneficial, or am I giving them "busy work" so they do not interfere with my workflow? Does the student feel I am approachable to answer questions or is he/she afraid to ask questions for fear of being ridiculed? The answers to these questions can help a preceptor determine if they are providing an environment that promotes learning and professional development or one that is potentially hindering it (Hammer, 2003).

Another roadblock in the development of professionalism is a students' exposure to a pharmacist who is involved in illegal or unethical practices. Although unethical examples like Robert Courtney are a rarity in the pharmacy profession, they do occur (CNBC, 2011). Experiences with unethical behaviors hinder the professional socialization process and may result in a range of negative outcomes for the student that may include anything from an unethical act on the part of the student or an emotional toll from incorporation in uncomfortable situations.

Finally, a major challenge in maintaining professionalism is students' ability to develop a balance between a patient focused practice and a business focused practice. Unfortunately pharmacists have to contend with this balance on a daily basis. The shortage of pharmacists, increasing healthcare costs, and cost reduction strategies have forced pharmacists to shift attention away from the patient and toward operating a business (Knapp, 2005). Pharmacists should frequently re-assess how they conduct their business to ensure that, while maintaining a marketable profession, they have not sacrificed patient care (Prince, 2003; Chalmers, 1995; Lipowski, 2003).

\section{Responsibilities of the Student}

Becoming a professional pharmacist does not occur overnight. Pharmacy students must continually strive to display the traits of professionalism. Although pharmacy educators are charged with responsibility of teaching professionalism to every student, it still remains the student's responsibility to actively cultivate and demonstrate professionalism. Pharmacy students should take the initiative to enhance their own professional development as well as assisting their fellow classmates. Encouraging development can be done by active participation in classroom activities, dressing appropriately, becoming involved with pharmacy organizations and student government, volunteering to assist underclassman, and participating in community service. An important point for all professional students to remember is that acting professional is not the same as being professional (Hafferty, 2006; Hatem, 2003). A bicycle wheel has been used as a simple way to illustrate this concept (See Figure 1) (Chisholm, 2006; Roth, 2009). The hub of the wheel represents the core values of the pharmacist that includes altruism, beneficence, and the fiducial relationship with their patients. The spokes of the wheel represent the different traits or behaviors of professionalism which include: responsibility, honesty and integrity, respect for others, commitment to excellence and care and compassion. The tire represents the activities and duties of a pharmacist in which the professional traits are displayed including patient care, scientific discovery, application, scholarship, teaching, professional service, and leadership. As depicted in the figure, if one lacks the core values that comprise the hub of the wheel, then the professional behaviors that are displayed will likewise lack strength and substance--just as a bicycle tire would lack strength, if it did not have a solid hub (Roth, 2009; AACP 2009). 


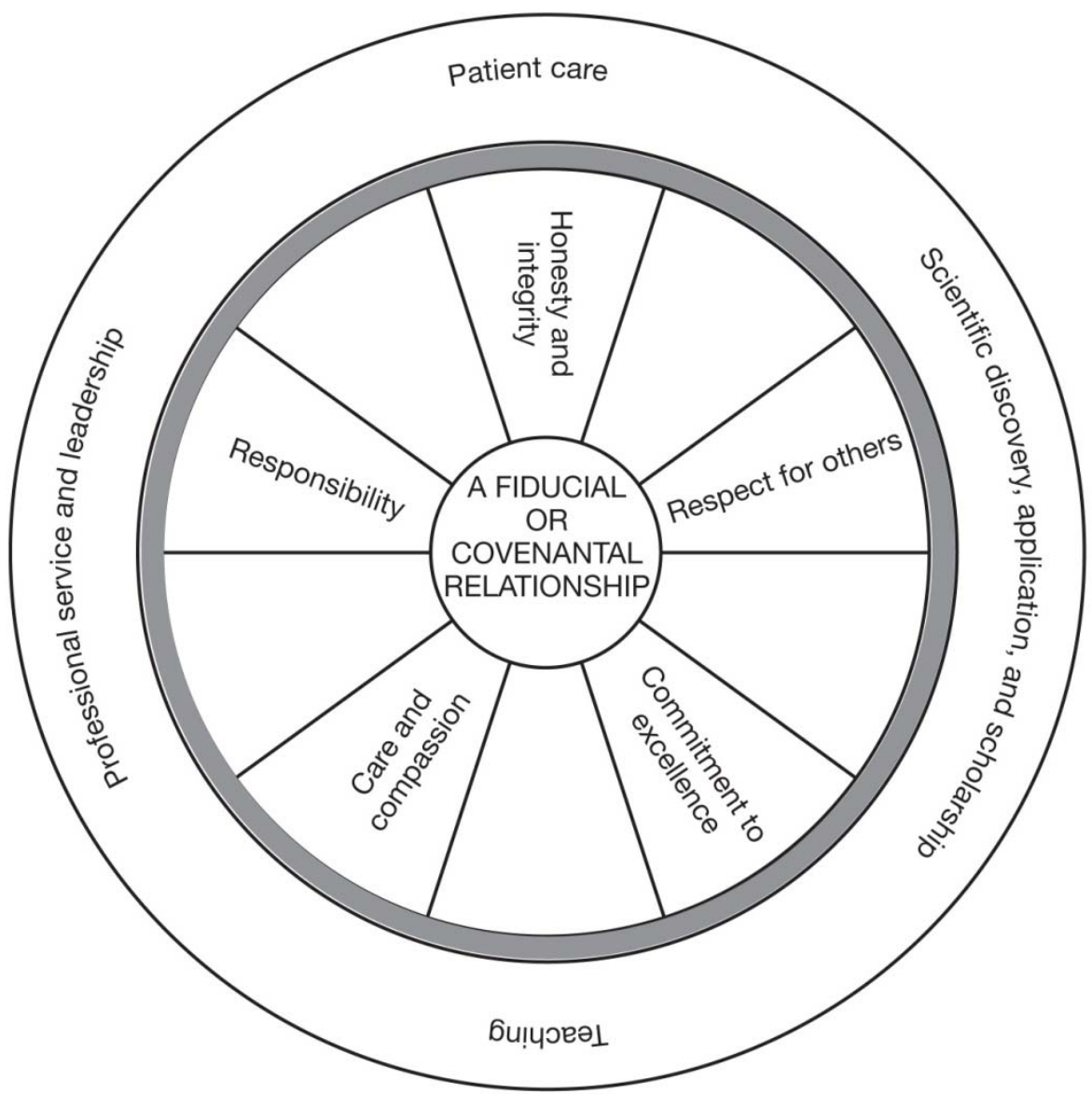

Figure 1. Being a Professional

In this bicycle wheel analogy, the six tenets of professionalism comprise the spokes of the tire (Hammer, 2003; ABIM, 2001). Pharmacy students should strive to display all of these tenets when interacting with other professionals as well as patients and their family members. Accepting responsibility is an extremely important step in the professional socialization of a pharmacy student. When students progress through the pharmacy curriculum, they should be encouraged to make therapeutic decisions for their patients and be able to defend them. By making important decisions and defending these with supporting evidence from the literature, students take on greater responsibility for their actions as future healthcare providers. This growth in professional behavior, in turn, builds the students' self-confidence which is an invaluable trait for a practicing pharmacist.

Professional growth and confidence are particularly important when decisions result in a negative outcome. A true test of one's character can be displayed when one freely accepts accountability for making the wrong decision. In a recent survey conducted at six different colleges of pharmacy, responsibility was reported to be one of the two key attributes of professionalism. With all four groups of respondents (students, faculty, preceptors and administrators) reporting that responsibility and competency were the common traits of professionalism (Thomspson, 2008). Accepting responsibility shows a commitment to excellence and displays honesty and integrity, and these qualities should be lifelong goal of all pharmacists. Pharmacists have an obligation to the society they serve to consistently acquire and deliver accurate knowledge in order to facilitate the best possible outcome for their patients (Boyle, 2006). For professional students, honesty begins in the classroom. Cheating or academic dishonesty early in a student's professional education is cause of great concern for faculty members. Not only for the act of cheating but the potential for dishonest behavior when working with patients and other healthcare providers. One act of dishonesty could result in the permanent loss of trust from one's patients and colleagues. 


\section{Responsibilities of the Educator}

Although the pharmacy student assumes the primary responsibility of developing professionalism, faculty members also play an essential role. All pharmacy educators including administrators, professors, and preceptors serve an integral role in the professional socialization process. One of the major responsibilities of pharmacy educators is to develop a clear and concise definition of professionalism. The need for an established definition is due to the multitude of definitions for professionalism amongst institutions and healthcare providers (Hammer, 2003; APhA/AACP, 2000). By providing students with a clear definition of what constitutes professionalism, faculty members can more accurately assess the students' behaviors and actions. A standardized definition also prevents possible confusion as to what is considered unprofessional behavior and possible allegations of students being treated differently or unfairly. Using examples of unprofessional behavior to help students grasp the concept of professionalism has been incorporated by some institutions (Bouldin, 2002). However, this tactic may prove to be inappropriate, if students are only able to identify and discuss unprofessional behaviors and cannot articulate the attributes and qualities that define a professional. Institutions should also provide faculty members with instructional programs and seminars on teaching professionalism. Incorporating these learning sessions ensures that all faculty members possess the necessary skills to teach professionalism and are effective role-models for their students (Steinert, 2005). Therefore; students are less likely to receive mixed messages from their instructors regarding what is or is not considered professional.

The admissions committee serves as a filtering process in which students are separated into those who will become healthcare professionals and those who will not. While grade point averages (GPAs), Pharmacy College Admission Test (PCAT) scores, and other academic achievements are important points in assessing the potential student, the admissions committee should also review a student's professional attributes. These include community service and volunteer work, involvement in student organizations, student government participation and displaying the desire to help others (APhA/AACP, 2000). Using proper interview techniques when evaluating a student allows the committee to separate the students that aspire to help others and possess the qualities needed to become a professional from those that are simply interested in a lucrative career.

Although the vast majority of pharmacy students' "hands on" experience occurs in the last year of school, it remains important to utilize the early part of their curriculum and introduce professionalism practices, so that students do not remain solely focused on lectures and tests as their preparation for their final year. Professionalism has been noted as a quality that cannot be solely learned from a textbook; therefore, the first years of pharmacy school are extremely important in the development of professionalism (Hammer, 2003; Chisholm, 2006; Steinert, 2005). A recent publication described a professionalism program that requires newly admitted pharmacy students to read four short stories that focus on professionalism during the summer prior to their first professional year. When the students first arrive on campus for orientation, they are divided into small groups and with the direction of faculty members, they discuss the readings and their relevance to the practice of pharmacy (Bumgarner, 2007). Faculty members found that this program helped the newly admitted students in fostering professional attitudes and behaviors (Bumgarner, 2007). During these early years, when students are obtaining "textbook knowledge," they should also begin to inculcate the tenets of professionalism including: excellence, accountability, duty, honor and integrity.

Another means for promoting professionalism in the early years of pharmacy curriculum is during Introductory Pharmacy Practice Experiences (IPPE). IPPEs can represent the early development of professionalism within an actual health care setting. Faculty should use IPPEs to allow students to apply the extensive "textbook knowledge" they have worked so hard to achieve. Accomplishing application of learning will allow students a better understanding of the professionalism tenets and development of self-confidence that will begin to perfect their communication skill set (Brown, 2009).

Advanced Pharmacy Practice Experiences (APPE) is the culmination of pharmacy students' four years of professional education and is also the final step for pharmacy educators to help students hone their professional behaviors. Although students who have completed their APPEs will graduate soon, becoming licensed and beginning to practice as professionals, they will continuously seek to improve and maintain professionalism as long as they choose to serve the public. APPEs provide preceptors with a valuable opportunity to not only further a student's education through practice but to evaluate the student's professional development. Preceptors should provide an environment that is challenging but also conducive to learning (Hammer, 2003). APPEs should involve a broad view of the pharmacy profession thus better preparing the graduating student for whatever career path they choose (APhA/AACP, 2000). Since APPEs are one of the last learning opportunities during pharmacy students' professional education, students are expected to display an exceptional knowledge base, a high level of professionalism, and a 
strong work ethic.

Preceptors also have a responsibility to students which includes providing them with explicit instructions about requirements and expectations, providing feedback about performance concerns in a timely fashion, and completing an accurate evaluation of students' accomplishments during the rotation (Boyle, 2007; Brainard, 2007). Furthermore, preceptors should not be reluctant to assign failing grades to students who have not met the requirements of an APPE.

Concerns have been raised that evaluation of students' professionalism does not comprise enough of the final APPE grade (Hammer, 2006; Boyle, 2007). As a result of this disproportionality, some students received failing assessments for professionalism but still passed the rotation due to other sections of the evaluation carrying more weight. To combat these issues, it is strongly recommended to frequently re-educate preceptors on how to appropriately evaluate students (Hammer, 2003; Chisholm, 2006; APhA/AACP, 2000). Some colleges of pharmacy have even gone a step further by re-structuring their entire APPE evaluation process. For example, the University of Maryland School of Pharmacy introduced three specific professional behaviors into the APPE evaluation in 2001 (Hammer, 2006). In order to successfully complete the rotation, students were required to receive "outstanding" or "competent" ratings in all three categories of professionalism. Inability to receive these ratings resulted in failure of the APPE, regardless of scores achieved in other categories of the evaluation (Hammer, 2006). The incorporation of these changes demonstrated the university's unwavering dedication to promoting student professionalism.

\section{E-professionalism}

Faculty members have noticed a new form of unprofessional behavior that has become increasingly more common with pharmacy students. These behaviors are directly linked to the exponential advances in our society's technology and through the increase in e-learning, or electronic media, information, and technologies in education. These technological advances during the past two decades have revolutionized the way our society and our students interact and communicate. Face to face conversations, telephone calls, and letters have taken a backseat to email, text messages, and social networking websites. Although these innovations are a very beneficial, convenient and sometimes an enjoyable way to share information, they can cause many pitfalls for a young professional. E-professionalism involves how we conduct and represent ourselves when using e-communication, or "high tech" forms of communication (Kaltschmidt, 2008; Guseh, 2009). E-communication requires some additional tips to translate into proper e-professionalism, because there are unique scenarios that could result in potentially unprofessional behaviors.

Email is one of the most common forms of e-communication used by healthcare professionals in today's workplace (Kaltschmidt, 2008). However, care should be taken when sending emails to ensure that the reader accurately receives the intended message. Improper forwarding and incorrect email addresses can result in inappropriate correspondence with negative outcomes for the student. Proper grammar, punctuation, and spelling are key elements of composing professional emails and should be used during all pharmacy school related communications. Students should make a conscious effort to avoid slang language and improper capitalization as these can affect the tone of an email. Extreme care should be taken by students when composing any form of electronic messages to ensure the proper tone, since the reader can only use the words that are chosen to interpret the message. Proper word choice can have a profound impact on whether an e-message is received the way the sender intended. Similarly, using all capitalized words can be taken as shouting or yelling and italicized words can force emphasis onto a recipient. Capitalization of all words in a professional setting should be avoided and italicization should be utilized sparingly and not for overly, emotional emphasis. Lastly, the student's email address (i.e. student@student.com) should be composed to reflect a professional decorum to any potential recipients. Particular emphasis should be made for students to maintain not only a professionally named pharmacy school email account name, but also a professional personal email account name in case it is ever used for communicating with other health care providers (Jannsen, 2009).

Distance learning sites for pharmacy schools rely heavily on an internal network of e-communication, and students should be educated to maintain professional communicative techniques and also be made aware of the unique challenges of an online environment. Part of this process involves responsibility to peers and instructors by checking their email and discussion boards daily for up-to-date information and important announcements. When posting to a discussion board, students should be aware that professional academic behavior involves providing constructive criticism and that educational discussion boards are not personal forums to vent frustrations. Properly titling of any posting on a discussion board is also key in recognizing the needs of the group versus oneself since not every student 
may need to read a particular posting. Additionally, repetitive postings and emails that do not allow for adequate response time from recipients are unprofessional and can boarder on harassment. Students should be continuously mindful that discussion boards are accessible by other students, administrators, and faculty and should be given examples to help guide their professional actions.

E-learning environments not only require that students' to maintain boundaries over their actions, but they must also maintain boundaries over distribution of content. An important aspect of e-professionalism is students knowing which topics are appropriate for an online forum and which topics are best addressed in a traditional in-person setting. Recognizing the appropriateness of a topic's setting should be modeled to students by educators and detailed with examples in e-professional handouts. Although personal correspondence and photos may be appropriate for online school communication sites in the proper setting, the ease of "cut and paste" functions as well as photo shopping can lead to the dissemination of inappropriate materials as well as potentially negative consequences for students. Similarly, cutting and pasting of another's work or plagiarism should not be tolerated, and its definition should be well defined in e-professional guidelines. Academic dishonesty policies should directly address, define, and continually re-assess elements of e-communication, and these policies should then be referenced in professionalism guidelines. An online environment presents unique challenges in regards to student accountability, and students must be aware good e-professionalism does not include behaviors like sharing passwords, sharing or completing another student's work, submitting another student's work, sharing work or projects between different class years, or conducting independent work as a group.

E-communication outside of pharmacy school discussion boards and email include social networking websites like Myspace, Facebook, and YouTube. These sites have exhibited increasing popularity among college students in the last several years. Facebook alone has reported 100,000 new users per day with $80 \%-90 \%$ of these accounted for by U.S. college students (Cain, 2008). A recent survey of 299 pharmacy students revealed that $53 \%$ had logged into Facebook at least once a day for an average of twenty-two minutes (Cain, 2009). Due to the overwhelming popularity of these websites and the ability for users to post virtually anything, these new forms of communication can be a source of unprofessional behaviors. In a recent survey of U.S. medical schools, $60 \%$ reported incidents of students posting unprofessional content on the internet (Chretien, 2009). Complicating this problem is the variable privacy settings of these sites which has blurred the line separating any user's private life and public life (Cain, 2008; Guseh, 2009). A lack of privacy has resulted in unprofessional content being posted online, and students involved in the posted material not always being aware of the negative impact that results (Farnan, 2008).

To what extent these websites should be monitored by educators and school administrators continues to be a topic of great debate. First amendment rights of free speech, individual privacy, and safety of the student body are just a few of the many issues that add to the complexity of this problem (Cain, 2008). However, for pharmacy and other professional students the question of whether or not your "online persona" accurately reflects who you are as a person and a future healthcare provider should be of primary concern (Cain, 2009). Healthcare professionals have always prided themselves in displaying attributes of altruism, trustworthiness, and accountability. Therefore, it should be expected that an "online persona" of a healthcare professional should reflect the same qualities. Therefore professional educators should establish guidelines or policies that address unprofessional online behaviors, promote an awareness of this newly developing aspect of professionalism, and to educate and guide students in maintaining an e-professional reputation (Cain, 2008; Thompson, 2008; Guseh, 2009; Chretien, 2009). Pharmacy students should carefully assess how their online actions could be viewed. Some important questions student should ask themselves include: does my online profile accurately reflect who I am as a professional? Would I want one of my patients to view my profile? Am I comfortable with a faculty member viewing my pictures, comments, and blogs? These questions can help a student determine if their online image is potentially unprofessional.

\section{Conclusion}

Colleges of Pharmacy must develop methodologies to aid in the development of professionalism among pharmacy students in all types of learning environments, whether a student attends a traditional campus or a distance campus. These methodologies may include: the development and continuation of professional pharmacy organizations on campus, extending and enhancing introductory pharmacy practice experiences (IPPEs), and instituting consistent reminders of the students' professional commitment through activities such as taking and signing a pledge of professionalism and participating in a white coat ceremony. Increasing the number of practicing pharmacist role models that students interact with in the classroom can be a beneficial step enhancing and increasing student professionalism. 
Professionalism is one of the most important attributes a pharmacy student possesses, and cannot always be learned from reading a textbook or watching a lecture, but instead professionalism should be developed through practice experiences and by interactions with professional mentors and role-models. Faculty members and other healthcare professionals help shape pharmacy students by providing an example for students to follow. To become a true professional, students must not only display the behaviors of a professional but they must realize that the fiducial relationship with the patient is at the very core of professionalism. Altruism, accountability, excellence, duty, honor, integrity and respect for others are all important attributes that students should strive to exhibit and encourage among their colleagues. Without the trust of the patient as the primary focus these traits lack definition and meaning (Hammer, 2003; ABIM, 2001). It is the responsibility of all pharmacy practitioners to nurture a trusting relationship with their patients so that the utmost care can be provided; thereby fulfilling the obligation pharmacy professionals have to the society they serve. With the development of distance learning in the education of pharmacists, the need to maintain professionalism has become more important than ever. External (personal) and internal (academic) communication networks can easily blur together without established boundaries. Continuous feedback is necessary to ensure professionalism standards are being maintained by students. Feedback from the preceptors may also aid in achieving the higher standard of professionalism pharmacy students must attain to become effective, patient-centered health care professionals.

\section{References}

American Board of Internal Medicine. (2001). American Board of Internal Medicine Committees on Evaluation of Clinical Competence and Clinical Competence and Communication Programs. American Board of Internal Medicine, 5-6.

American College of Clinical Pharmacy. (2009). Tenets of professionalism for pharmacy students. Pharmacotherapy, 29, 757-759. http://dx.doi.org/10.1592/phco.29.6.757

American Pharmaceutical Association Academy of Students of Pharmacy--American Association of Colleges of Pharmacy APhA-ASP/AACP Committee on Student Professionalism. (July 2011). Pharmacy professionalism toolkit for students and faculty. Retrieved from http://www.pharmacist.com/AM/Template.cfm?Section=Professionalism_Toolkit_for_Students_and_Faculty

American Pharmaceutical Association Academy of Students of Pharmacy--American Association of Colleges of Pharmacy Council of Deans Task Force on Professionalism. (2000). White paper on pharmacy student professionalism. J Am Pharm Assoc (Wash), 40(1), 96-102.

American Society of Health-System Pharmacist. (2008). ASHP statement on professionalism. Am J Health-Syst Pharm, 65, 172-174. http://dx.doi.org/10.2146/ajhp070397

Bouldin AS, \& Bentley JP. (2002). Using the critical incident technique to investigate the concept of pharmacy student professionalism. Am J Pharm Educ, 66, $96 \mathrm{~S}$.

Boyle C. (2006). Fostering leadership and professionalism. Am J Health-Syst Pharm, 63(3), 210-212. http://dx.doi.org/10.2146/ajhp050373

Boyle CJ, Beardsley RS, \& Morgan JA, et al. (2007). Professionalism: A determining factor in experiential learning. Am J Pharm Educ., 71(2), 31. http://dx.doi.org/10.5688/aj710231

Brainard AH, \& Brislen HC. (2007). Viewpoint: learning professionalism: A view from the trenches. Acad Med., 82(11), 1010-1014. http://dx.doi.org/10.1097/01.ACM.0000285343.95826.94

Brown D, \& Ferrill MJ. (2009). The taxonomy of professionalism: Reframing the academic pursuit of professional development. Am J Pharm Educ., 73(4), Article 68. http://dx.doi.org/10.5688/aj730468

Bumgarner GW, Spies AR, \& Asbill CS, et al. (2007). Using the humanities to strengthen the concept of professionalism among first-professional year pharmacy students. Am J Pharm Educ., 71(2), 28. http://dx.doi.org/10.5688/aj710228

Cain J, Scott DR, \& Akers P. (2009). Pharmacy students' Facebook activity and opinions regarding accountability and e-professionalism. Am J Pharm Educ., 73(6), 104. http://dx.doi.org/10.5688/aj7306104

Cain J. (2008). Online social networking issues within academia and pharmacy education. Am J Pharm Educ., 72(1), 10. http://dx.doi.org/10.5688/aj720110

Chalmers RK, Adler DS, \& Haddad AM, et al. (1995). The essential linkage of professional socialization and 
pharmaceutical care. Am J Pharm Educ, 59, 85-90.

Chisholm MA. (2004) Diversity: a missing link to professionalism. Am J Pharm Educ, 68(5), Article 120. http://dx.doi.org/10.5688/aj6805120

Chisholm MA, Cobb H, \& Duke L, et al. (2006). Development of an instrument to measure professionalism. Am J Pharm Educ, 70(4), 85. http://dx.doi.org/10.5688/aj700485

Chretien KC, Greysen SR, Chretien JP, \& Kind T. (2009). Online posting of unprofessional content by medical students. JAMA, 302(12), 1309-1315. http://dx.doi.org/10.1001/jama.2009.1387

CNBC. (July 2011). American Greed: Some People Will Do Anything for Money. Case 1: Deadly Rx for Greed. Retrieved from http://www.cnbc.com/id/23182570

Cruess, RL. (2006). Teaching Professionalism: Theory, principles, and practices. Clin Orth Rel Res, 449, 177-185.

Doshi AE. (2003). Professionalism in pharmacy. Student-Pharmacists' policies target professionalism. J Am Pharm Assoc, 43(4), 455-456.

Farnan JA, Paro JA, \& Higa J, et al. (2008). The YouTube generation: Implications for medical professionalism. Perspect Biol Med., 51(4), 517-524. http://dx.doi.org/10.1353/pbm.0.0048

Guseh JS, Brendel RW, \& Brendel DH. (2009). Medical professionalism in the age of online social networking. $J$ Med Ethics., 35(9), 584-586. http://dx.doi.org/10.1136/jme.2009.029231

Hafferty F. (2006). Professionalism- The Next Wave. $N$ Engl $J$ Med., 355(20), 2151-2152. http://dx.doi.org/10.1056/NEJMe068217

Hammer D. (2006). Improving student professionalism during experiential learning. Am J Pharm Educ., 70(3), 59. http://dx.doi.org/10.5688/aj700359

Hammer DP, Berger BA, \& Beardsley RS, et al. (2003). Student Professionalism. Am J Pharm Educ, 67(3), Article 96. http://dx.doi.org/10.5688/aj670396

Hatem CJ. (2003). Teaching approaches that reflect and promote professionalism. Acad. Med, 78, 709-713. http://dx.doi.org/10.1097/00001888-200307000-00010

Jannsen M. (2009). Social networking and e-professionalism. Am J Health Syst Pharm., 66(18), 1672.

Jones, J. (December 3, 2010). Nurses Top Honesty and Ethics List for $11^{\text {th }}$ Year. Retrieved from http://www.gallup.com/poll/145043/Nurses-Top-Honesty-Ethics-List-11-Year.aspx

Kaltschmidt J, Schmitt SP, Pruszydlo MG, \& Haefeli WE. (2008). Characteristics of effective electronic mail messages distributed to healthcare professionals in a hospital setting. J Am Med Inform Assoc., 15(2), 235-239. http://dx.doi.org/10.1197/jamia.M2503

Knapp KK, Quist RM, \& Walton SM, et al. (2005). Update on the pharmacist shortage: national and state data through. Am J Health-Syst Pharm, 62(5), 492-499.

Lipowski EE. (2003). Professionalism in pharmacy. Seeking the science angle in APhA policies. J Am Pharm Assoc, 43(4), 454-455. http://dx.doi.org/10.1331/154434503322226176

National Institute of Business Management. (1991). Ten Marks of a Professional Working Smart. 17(5).

Prince VT. (2003). Professionalism in pharmacy. $J$ Am Pharm Assoc, 43(4), 452-454. http://dx.doi.org/10.1331/154434503322226176

Roth MT, \& Zlatic TD. (2009). Development of student professionalism. Pharmacotherapy, 29(6), 749-756. http://dx.doi.org/10.1592/phco.29.6.749

Steinert Y, Cruess S, Cruess R, \& Snell L. (2005). Faculty development for teaching and evaluating professionalism: from programme design to curriculum change. Medical Education, 39, 127-136. http://dx.doi.org/10.1111/j.1365-2929.2004.02069.x

Thompson DF, Farmer KC, \& Beall DG, et al. (2008). Identifying perceptions of professionalism using a four-frame leadership model. Am J Pharm Educ., 72(4), 90. http://dx.doi.org/10.5688/aj720490

Thompson LA, Dawson K, \& Ferdig R, et al. (2008). The intersection of online social networking with medical professionalism. J Gen Intern Med., 23(7), 954-957. http://dx.doi.org/10.1007/s11606-008-0538-8 